\title{
AS CONTRIBUIÇÕES DE PAULO FREIRE NA EXPERIÊNCIA DO PROJETO EDUCATIVO DE INTEGRAÇÃO SOCIAL - PEIS
}

\section{PAULO FREIRE'S CONTRIBUTIONS IN THE EDUCATIONAL PROJECT FOR SOCIAL INTEGRATION - PEIS}

\author{
LEITE, Sandra Fernandes ${ }^{1}$
}

\begin{abstract}
RESUMO
O Projeto Educativo de Integração Social - PEIS propõe promover a inclusão digital e social de jovens, adultos e idosos por meio das tecnologias da informação e computação. Apresenta abordagem diferenciada e possível de ser aplicada na Modalidade Educação de Jovens e Adultos (EJA). Seu principal objetivo é oferecer aos educandos jovens, adultos e idosos uma educação que os façam participantes ativos do seu processo de ensino e aprendizagem, por meio do uso das tecnologias da informação e computação, visando à construção e ao exercício da cidadania e sua integração social. A metodologia baseia-se nas concepções de Paulo Freire e tem como princípio educativo os saberes do educando intercalados ao conhecimento cientifico na figura do educador. O projeto entende a inclusão digital como algo que vai além de "alfabetizar" em informática, é também um caminho de socialização e melhoria da qualidade de vida. Aqui são apresentadas a origem, a evolução e as transformações das iniciativas do PEIS.
\end{abstract}

PalaVRAS-Chave: Educação de Jovens e Adultos; Paulo Freire; Inclusão Digital

\begin{abstract}
The Educational Project of Social Integration - PEIS proposes to promote the digital and social inclusion of young people, adults and the elderly through information and computer technology. It presents a differentiated and possible approach to be applied in the Youth and Adult Education (EJA). Its main objective is to offer young learners, adults and the elderly an education that will make them active participants in their teaching and learning process, through the use of information and computer technology, aiming at the construction and exercise of citizenship and its social integration. The methodology is based on the conceptions of Paulo Freire and has as educational principle the knowledge of the student interspersed with scientific knowledge in the figure of the educator. The project understands digital inclusion as something that goes beyond "literacy" in computer science, it is also a way of socializing and improving the quality of life. Here, the origin, evolution and transformations of the Educational Project of Social Integration (PEIS) initiatives are presented.
\end{abstract}

KEY WORDS: Youth na adult education; Paulo Freire; Digital inclusion

\footnotetext{
${ }^{1}$ Professora Doutora da Faculdade de Educação da UNICAMP. e-mail: sfleite@unicamp.br
} 


\section{BREVe Histórico}

O Projeto Educativo de Integração Social - PEIS é uma continuidade de uma iniciativa anterior que tem suas origens no ano de 1982, nas dependências da Pontifícia Universidade Católica de Campinas - PUCCAMP. Esta iniciativa tinha o objetivo de preparar vinte e sete funcionários da Prefeitura Municipal de CampinasSP para os Exames Supletivos do Estado. O nome utilizado era "Projeto Supletivo Preparatório aos Exames de $1^{\circ}$ e $2^{\circ}$ Graus". Em 1995 o projeto deixou as dependências da Pontifícia Universidade Católica de Campinas (PUCCAMP) e passou então a funcionar na Escola Estadual Carlos Gomes, na região central da cidade de Campinas - SP. Este processo de mudança mostrou que o propósito do programa não se restringia mais a preparar os educandos para os exames supletivos. Baseado na concepção de Paulo Freire, o novo entendimento era de formar o ser humano, buscando uma educação autônoma e libertadora. O nome do projeto foi alterado para "Projeto Educativo de Integração Social-PEIS" (SOUZA, 2011).

No ano de 1998 o projeto mudou novamente de local, passando a funcionar nas dependências do Colégio Técnico da Unicamp (COTUCA), onde permaneceu até o ano de 2013. Dentro do Grupo de Estudos e Pesquisas em Educação de Jovens e Adultos - GEPEJA da Faculdade de Educação da Unicamp, o projeto se consolidou como sendo um espaço de garantia de oportunidade de estágio supervisionado para os educandos dos cursos de graduação em Pedagogia e Licenciatura da Unicamp, além de oferecer um espaço para a troca de experiências e aprendizagens em sala de aula. Os licenciados, sob acompanhamento, atuavam como docentes no planejamento das atividades e na preparação da aula, do material didático e da avaliação. O estágio se concretizava como um espaço para a análise da formação do educador e de reflexão que ampliava a compreensão acerca das especificidades do educando adulto. Em um primeiro momento, os educadores eram educandos dos cursos de licenciaturas da Unicamp que necessitavam realizar seus estágios de docência. Com passar do tempo, o perfil dos educadores foi se alterando com a chegada de mais graduados de outras áreas, mestrandos e doutorandos.

Segundo Souza \& Leite (2010, p. 04), o Projeto PEIS tinha como principal objetivo proporcionar condições para os educandos que desejavam retornar ou iniciar seus estudos. Nos documentos de criação do projeto optou-se que o educando do PEIS deveria ter mais de 18 anos, tornando o projeto voltado exclusivamente para a Educação de Adultos.

As atividades no Projeto PEIS aconteciam somente aos sábados, seguindo o calendário de aulas da Unicamp e do Colégio Técnico COTUCA, no período da manhã. Utilizava algumas salas de aula do Colégio COTUCA, localizado na região central de Campinas. Eram oferecidas aulas de alfabetização e disciplinas do currículo básico do Ensino Fundamental e Médio, sendo que cada aula tinha duração de uma hora. 
Sobre o perfil do educando que cursou o projeto neste período em que esteve alocado no Colégio COTUCA, Souza (2013) em sua pesquisa relata que a maioria dos educandos eram mulheres, com idade média de 50 anos, residentes em Campinas e, até 2007, eram em sua maioria casadas. A partir dessa data, o número de solteiros, divorciados e viúvos foi aumentando gradativamente, bem como também o número de homens. Ainda assim, o número de mulheres que continuavam a participar do projeto permanecia superior ao de homens.

Quanto às motivações que trouxeram os educandos a procurarem o Projeto PEIS, Souza (2013) relata ser uma opção para iniciar ou retomar os seus estudos; os resultados obtidos apontaram que até 2006 o objetivo dos educandos que ingressaram no projeto era o aprendizado sistematizado do conteúdo escolar. Procuraram o projeto, pela facilidade de estudar somente aos sábados. A partir de 2006, o Projeto passou a ser visto como um espaço que também possibilitava o convívio social, a afetividade e a sociabilidade.

Ao longo de 35 anos de existência, diversos estudantes de Pedagogia e Licenciaturas passaram pelo Projeto PEIS durante a sua graduação. Alguns deles, mesmo após a conclusão dos estágios, ou atividades de observações permaneceram como voluntários. O Projeto PEIS também foi objeto de pesquisas acadêmicas, tendo sido realizadas pesquisas de Mestrados, Doutorados e Trabalhos de Conclusão de Curso (TCC). Dessa experiência surgiram artigos produzidos e apresentados em congressos e/ou seminários no Brasil e no Exterior. Uma experiência marcante observada ao longo do projeto foi o retorno de educandos do Projeto PEIS como docentes, contribuindo com suas atividades e trazendo a sua experiência acumulada e vivência no próprio projeto.

O Projeto PEIS apresentava uma prática metodológica diferenciada ao destacar o trabalho com o educando adulto e idoso. Esse perfil de educando exige uma dinâmica e uma proposta de trabalho muito particular e personalizada. Buscouse ir além da mera reprodução de conteúdo, colocando-se como uma opção de aprendizagem verdadeira, que partia do conhecimento do educando, mas que não se limitava a responder às suas curiosidades, mas construir conjuntamente um saber real, voltado para um público que tinha interesses, desejos e objetivos bem claros com relação à educação.

Apesar de não emitir uma certificação como as escolas regulares, constatou-se que educandos do Projeto PEIS participaram de Programas do Governo de certificação, como o ENCCEJA ${ }^{2}$, ENEM ${ }^{3}$, vestibulares e até mesmo do PROUNI ${ }^{4}$. Embora a dinâmica das aulas não fosse voltada para a realização desse tipo de certificação, isso não os impediu de participarem ou de levarem para sala de aula questões referentes a tais exames. Dessa forma, os educandos encontraram no

\footnotetext{
${ }^{2}$ Exame Nacional para Certificação de Competências de Jovens e Adultos - ENCCEJA.

${ }^{3}$ Exame Nacional do Ensino Médio - ENEM.

${ }^{4}$ Programa Universidade para Todos - ProUni.
} 


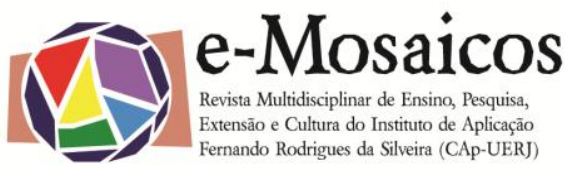

DOI: 10.12957/e-mosaicos.2017.30907

Projeto PEIS um espaço para uma aprendizagem significativa, com o trabalho sempre voltado para o seu desenvolvimento. Essa abordagem permitia ao educando sentir-se confiante para retornar ou permanecer na sala de aula.

Em 2014, o Colégio COTUCA precisou passar por uma reforma e o Projeto PEIS foi realocado em quatro salas de aula no Prédio Anexo da Faculdade de Educação da Unicamp. Com a instalação do PEIS na Faculdade de Educação da Unicamp, novas possibilidades foram se tornando possíveis. Dentro das mudanças, o PEIS passou a trabalhar com as demandas de seus educandos levantadas durante as avaliações dos trabalhos realizados. Como resultado, a primeira proposta foi o projeto de um curso de alfabetização e inclusão digital para os educandos.

\section{O Curso Alfabetização e Inclusão Digital de Jovens, Adultos e Idosos}

No primeiro semestre de 2015 os próprios educandos sentiam a necessidade de terem aulas de computador e conhecerem melhor as tecnologias. A inclusão digital era uma reinvindicação antiga dos educandos que frequentaram e ainda frequentam o programa e estava em pauta em todos os debates acerca das "possíveis" melhorias do projeto. Um objetivo específico desse projeto é proporcionar uma educação de qualidade, autônoma e libertadora, sobretudo, a partir da inclusão digital, que é vista como instrumento de construção e exercício da cidadania.

O objetivo geral do curso foi promover a inclusão digital e social de jovens, adultos e idosos por meio das tecnologias da informação, vistas como instrumento de construção e exercício da cidadania. Incluir digitalmente e não apenas alfabetizar o jovem e o adulto em informática, mas também melhorar a sua condição social a partir do manuseio do computador e de dispositivos móveis. Assim, a informática passa ao cotidiano dos educandos jovens, adultos e idosos, mantendo-os atualizados com as novas tecnologias e facilita a interação e integração entre gerações diferentes (pais, filhos, netos) na cultura digital e na sociedade da informação. 0 projeto acredita que as relações de ensino e aprendizagem, pautadas no diálogo, são as chaves para a uma educação libertadora.

A partir dessa mudança, o Projeto passou a trabalhar com o público da EJA estabelecido a partir da LDB no 9394/1996, ou seja, atender os jovens pouco escolarizados, os adultos e os idosos. Ainda hoje a maioria dos cursos de licenciatura não trabalha com a temática da modalidade EJA, quando muito há disciplinas teóricas que abordam a modalidade somente em seus aspectos histórico e legal. Diante dessa lacuna, é comum o educador acreditar que trabalhar com jovens pouco escolarizados, adultos e idosos é apenas uma questão de adaptação do trabalho realizado com crianças e adolescentes. De acordo com Souza (2013, p. 37),

deste modo, o educador do projeto, que também é educando da Universidade, aprende na prática, em sala de aula e nas reuniões pedagógicas que o educando(a) da modalidade EJA exige outros 


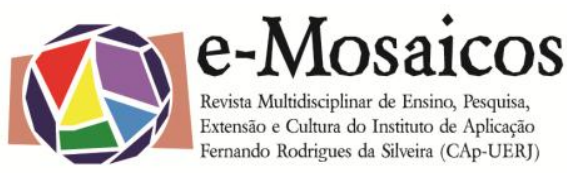

DOI: $10.12957 /$ e-mosaicos.2017.30907

processos de formação e, por isso, não é possível uma reutilização da pedagogia que os cursos de licenciatura pregam para o trabalho no ensino regular.

\section{Procedimentos Metodológicos}

No que diz respeito à modalidade EJA, segundo Leite (2013), o Brasil demorou muito na implementação de uma escola para a maioria da população. Ao constituí-la, não considerou as características específicas e necessidades dessa escola. A situação é mais crítica quando é para aqueles que não tiveram o acesso ou foram obrigados a abandoná-la. Esses educandos, ao retornarem à escola, não encontram condições favoráveis às suas características, histórias de vida e visão de mundo. São vistos como sujeitos que não trazem nada para a escola. $O$ país carrega um passado de omissão, exclusão e de negação do direito amplo à educação.

\section{A Educação de Jovens e Adultos}

Ao longo dos últimos anos, a modalidade EJA vem passando por um processo de redução de matrículas em cursos de EJA em praticamente todo o país. Contudo, isso não significa que a demanda por essa modalidade de educação tenha caído. 0 Brasil continuava a ter aproximadamente 4 milhões de pessoas atendidas pela EJA (IBGE, 2010).

Leite (2013) relata que, ao analisar a história da educação de adultos no Brasil, fica constatado que a educação de adultos e jovens não foi vista como prioridade. Suas ações foram, na maior parte dos casos, pouco definidas e sujeitas a interferências de todas as ordens. Não contou com a presença de uma força mais incisiva para garantir a ampla oferta pública, gratuita e dentro do sistema formal de ensino. Apesar do direito à educação estar presente no decorrer da história da educação do Brasil, muitas vezes se restringiu apenas ao texto legal ou à mera intenção. O que foi observado são ações pontuais e descontínuas, obtendo algum êxito em uma ou outra experiência. Não existiu uma preocupação em refletir as ações tomadas nas diversas reformas e programas implementados.

A Constituição Federal de 1988 garantiu o Ensino Fundamental como direito, a LDB 9394/1996 definiu o conceito de Educação Básica e a Emenda Constitucional 59/2009, entre outras, garantiram atenção à modalidade EJA. Para Leite (2013), ainda muito é necessário para consolidação do direito igualitário para todos. A EJA não foi concebida como uma continuidade da educação formal. Não existem ações claras que garantam a jovens e adultos o retorno à escola.

O Brasil vem modificando sua característica de população jovem. Está aumentando sua população adulta e idosa ao longo das últimas décadas. A modalidade EJA vem sendo espaço de atendimento crescente do público jovem. Mas tem de lidar cada vez mais com o aumento dos adultos e idosos. A modalidade EJA 
DOI: $10.12957 /$ e-mosaicos.2017.30907

não pode se resumir apenas às ações voltadas para inserção no mercado de trabalho.

A educação de adultos, e mais tarde a EJA, funcionou em blocos independentes e sem alguma condição concreta e segura de continuidade. É garantido o acesso ao ensino fundamental a partir da Constituição de 1988 e da LDB 9.394/1996. Porém, a consolidação da Educação Básica é ofertada de maneira dividida e trabalhada em instâncias, locais e instituições diferentes. São muitas barreiras para a conclusão de Ensino Médio para o público da EJA. Ainda assim, existe uma oferta de programas que contemplam o acesso e a formação básica, garantindo a conclusão da Educação Básica.

\section{Continuidade dos estudos}

Ao longo das últimas décadas foram implementadas políticas para a universalização do Ensino Fundamental para todos, incluindo a EJA. Mas estas ações não foram acompanhadas de propostas que assegurassem a permanência e a continuidade dos estudos de jovens e adultos que passaram a usufruir desse direito. Leite (2013) relata que as ações, projetos e programas implementados na EJA não dão conta de abranger todas as demandas de uma modalidade que possui diversas carências. São exemplos a alfabetização de jovens e adultos, o acesso a uma educação de qualidade aos que retornam e a necessidade de continuidade dos estudos.

Nem todos aqueles pertencentes a este público desejam o objetivo da educação voltada para a formação profissional. Este público fica carente de opções claras. Existe um leque de opções variado, mas falta a integração entre as ações propostas. Muitas vezes os educandos chegam a concluir um programa, mas não conseguem perceber uma indicação para continuar. As ações são focadas em si mesmas e não dialogam com outras possibilidades. Os programas estão atrelados à Educação Básica, mas por serem tão específicos, o educando não consegue vislumbrar a sequência da continuidade dos estudos. Cai sobre o próprio educando a responsabilidade de encontrar alternativas para garantir o seu direito.

Segundo Leite (2013), somente um grupo reduzido da EJA em uma determinada faixa etária e com um perfil específico - o jovem trabalhador consegue ser beneficiado com a terminalidade. A modalidade EJA, como oferta da Educação Básica, ainda está muito distante de se efetivar plenamente e para todo o público da EJA. As ações de política de atendimento a modalidade EJA priorizam os programas de atendimento ao jovem e ao adulto trabalhador. Em vez de diminuir o analfabetismo, observa-se 0 aumento do número de jovens que demandam escolarização nessa modalidade e a exclusão dos adultos e idosos que não se encaixam nos perfis propostos pelos programas.

$\mathrm{Na}$ EJA encontram-se educandos trabalhadores com histórias de uma escolarização marcada pelo abandono da escola e pela sobreposição da necessidade 


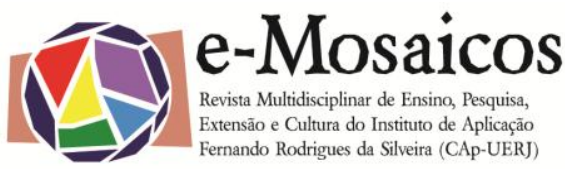

DOI: 10.12957/e-mosaicos.2017.30907

do trabalho à escola. Também estão os jovens com defasagem idade-série, acumulando repetências, evasões e dificuldades de acompanhar o ritmo imposto para a aprendizagem na escola regular. Estes educandos são direcionados para salas de EJA. Estão também os idosos que, mesmo não buscando o diploma ou certificação do sistema, possuem o desejo de retornar à escola.

Destaca-se a importância do educando ter orientações claras para planejar e executar o seu percurso de escolarização. Porém, as condições de apoiar e de garantir de fato a possibilidade de continuidade dos estudos são questionáveis. A educação para jovens, adultos e idosos não está atrelada aos interesses e às necessidades do público que ela atende e, embora a EJA seja apresentada como um direito pelo discurso governamental, ela possui inúmeros problemas, é precária e ainda muito distante de atingir a plena universalidade com qualidade.

Para Leite (2013), a EJA tem necessidade de políticas públicas que visam ao atendimento permanente e não apenas campanhas e ações com prazos determinados, desconectadas das reais demandas do público a qual se destinam.

Alguns trabalhos científicos apontam diferentes fragilidades das políticas públicas para a EJA. Haddad et al. (2002) relatam que a tendência de municipalização do atendimento aos jovens e adultos foi mais uma consequência da omissão dos poderes federal e estadual do que uma política de descentralização. Nesta mesma linha, Beisiegel (1998) destaca:

Guardadas as devidas cautelas, necessárias em virtude das flutuações da política da União para a educação de jovens e adultos, é possível afirmar que, desde a extinção da Fundação Educar, encontra-se em andamento um processo de transferência das atribuições da educação supletiva, que estão sendo deslocadas para os estados e, principalmente para os municípios (BEISIEGEL,1998, p. 241).

A educação de jovens e adultos converteu-se em uma forma de aceleração de estudos para adolescentes e jovens com baixo desempenho regular. Ribeiro (1999) considera que as deficiências do sistema escolar público regular são responsáveis pela crescente demanda de jovens nos programas educação de jovens e adultos, com o objetivo de tentar suavizar a defasagem idade/série.

Ressalta-se que nas Conferências Internacionais sobre Educação de Adultos (CONFINTEAs), com destaque na de número $V$, deu-se ênfase em uma definição precisa envolvendo a educação de adultos em âmbito internacional. Ela estabeleceu que a educação de adultos englobaria todo o processo de aprendizagem, formal ou informal, no qual os adultos podem desenvolver suas habilidades, aumentar o seu conhecimento, aperfeiçoar suas qualificações técnicas e profissionais, para seu próprio bem e da sociedade. Vale lembrar que o conceito de adulto pode variar de uma sociedade para a outra. É um conceito bastante subjetivo, pois em alguns 
e-Mosaicos - Revista Multidisciplinar de Ensino, Pesquisa, Extensão e Cultura do Instituto de Aplicação Fernando Rodrigues da Silveira (CAp-UERJ)

V. 6 - N. 13 - DEZEMBRO 2017 - ISSN: 2316-9303

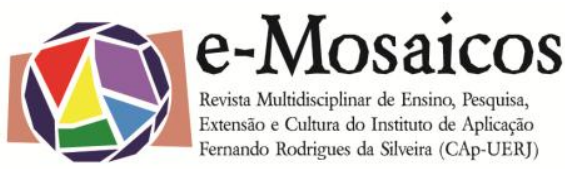

DOI: $10.12957 /$ e-mosaicos.2017.30907

países o jovem pode ser considerado adulto em função de sua posição no mercado de trabalho e/ou sustento de sua família ou comunidade.

Observa-se que para a educação de adultos ao longo do tempo foram atribuídas inúmeras finalidades, ampliando a concepção de educação e aprendizagem dos sujeitos na sociedade. O ideário da educação e da aprendizagem ao longo da vida é entendido como um meio para se chegar a um equilíbrio entre o trabalho e a aprendizagem, bem como ao exercício de uma cidadania ativa (DELORS et al., 2004, p. 105).

Considerando que a concepção da educação e aprendizagem ao longo da vida é abrangente, Gadotti (2009) considera que focar na aprendizagem sem se preocupar com o que se ensina e como se ensina, pode reduzir a EJA à instrumentalização e capacitação dos indivíduos para atender a demanda do mercado de trabalho. A CONFINTEA VI realizada em Belém em 2009 focalizou o reconhecimento da modalidade como um direito do cidadão, a alfabetização como base para se estabelecer a aprendizagem geral, inclusiva e integrada ao longo da vida para jovens e adultos.

No que diz respeito à formação do educador pode-se perceber que o educador de jovens e adultos demanda algumas características essenciais. Dentre elas estão a capacidade de solidarizar-se com os educandos, a disposição de encarar dificuldades, a confiança na capacidade de todos de aprender e ensinar. Torna-se, para tanto, essencial que esse educador conheça seus educandos, suas expectativas, sua cultura, as características e os problemas de seu entorno, suas reais necessidades de aprendizagem. Não pode faltar a esse educador o conhecimento dos conteúdos a serem ensinados e atualizados constantemente. Esse educador precisa refletir sobre sua prática, buscando sempre o seu aperfeiçoamento.

$E$ é nesse sentido que o PEIS também trabalha com a formação desse educador, tendo como referência a obra de Paulo Freire. Nos encontros de formação, os educadores do PEIS, na sua maioria alunos dos cursos de Pedagogia e de Licenciatura da Unicamp, através da leitura dos textos de Paulo Freire, podem não só ter contato com a sua obra, mas também discuti-la no contexto da prática, trazendo as concepções de Paulo Freire para além da teoria, aplicando na prática em sala de aula do PEIS.

Como resultado, observa-se que no trabalho com jovens e adultos é fundamental que o educador favoreça a autonomia dos educandos, estimulando-os a avaliar constantemente seus progressos e suas carências, ajudá-los a tomar consciência de como a aprendizagem se realiza. Compreendendo seu próprio processo de aprendizagem, os jovens e adultos tornam-se capazes de ajudar outras pessoas a aprender tornando-se esse fato essencial, uma vez que muitos deles já desempenham o papel de educadores na família, no trabalho ou na comunidade. 0 educador precisa estar atento para o fato de que o processo educativo não se encerra no espaço e no tempo da aula. O convívio em uma escola ou em outro tipo 
e-Mosaicos - Revista Multidisciplinar de Ensino, Pesquisa, Extensão e Cultura do Instituto de Aplicação Fernando Rodrigues da Silveira (CAp-UERJ)

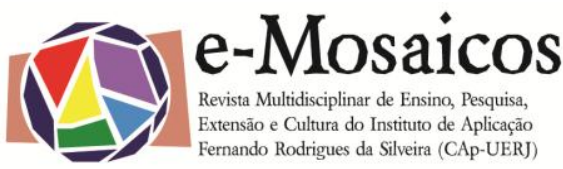

DOI: $10.12957 /$ e-mosaicos.2017.30907

de centro educativo pode se constituir como uma importante fonte de desenvolvimento social e cultural.

Falar das características esperadas de um educador que trabalhe com jovens e adultos parece fácil e até mesmo singular diante da sua formação. No entanto, é preciso destacar o aspecto "formação". A formação de educadores para atuarem em turmas de jovens e adultos trata-se de um desafio como política pública pelos poderes constituídos. Confirmando a necessidade de uma formação adequada às particularidades, encontramos no Parecer no 11/2000 a seguinte informação:

A formação dos docentes de qualquer nível ou modalidade deve considerar como meta o disposto no art. 22 da LDB. Ela estipula que a educação básica tem por finalidade desenvolver o educando, assegurar-lhe formação comum indispensável para o exercício da cidadania e fornecer-Ihe meios para progredir no trabalho e em estudos posteriores. (...)

Com maior razão, pode-se dizer que o preparo de um docente voltado para a EJA deve incluir, além das exigências formativas para todo e qualquer educador, aquelas relativas à complexidade diferencial desta modalidade de ensino. Assim esse profissional da licenciatura deve estar preparado para interagir empaticamente com esta parcela de estudantes e de estabelecer o exercício do diálogo. Jamais um educador aligeirado ou motivado apenas pela boa vontade ou por um voluntariado idealista e sim um docente que se nutra do geral e também das especificidades que a habilitação como formação sistemática requer (BRASIL, 2010, p. 56).

Cury, autor de tal parecer, alerta para a importância da preparação, da qualificação docente, lembrando, inclusive, a viabilidade através da capacitação em serviço, disposta na Resolução CNE/CEB 03/97. Em suas palavras:

A maior parte desses jovens e adultos, até mesmo pelo seu passado e presente, movem-se para a escola com forte motivação, buscam dar uma significação social para as competências, articulando conhecimentos, habilidades e valores. Muitos destes jovens e adultos se encontram, por vezes, em faixas etárias próximas às dos docentes. Por isso, os docentes deverão se preparar e se qualificar para a constituição de projetos pedagógicos que considerem modelos apropriados a essas características e expectativas. Quando a atuação profissional merecer uma capacitação em serviço, a fim de atender às peculiaridades dessa modalidade de educação, deve-se acionar o disposto no art. 67, II que contempla o aperfeiçoamento profissional continuado dos docentes e, quando e onde couber, o disposto na Res. CNE/CEB 03/97 (BRASIL, 2000, p. 57). 
O Parecer no 11/2000 apresenta uma análise conclusiva para a questão da formação do educador da EJA, quando diz:

... trata-se de uma formação em vista de uma relação pedagógica com sujeitos, trabalhadores ou não, com marcadas experiências vitais que não podem ser ignoradas. E esta adequação tem como finalidade, dado o acesso à EJA, a permanência na escola via ensino com conteúdo trabalhados de modo diferenciado com métodos e tempos intencionados ao perfil deste estudante. Também o tratamento didático dos conteúdos e das práticas não pode se ausentar nem da especificidade da EJA e nem do caráter multidisciplinar e interdisciplinar dos componentes curriculares. (BRASIL, 2000, p. 58)

Di Pierro e Graciano (2003) acrescentam:

Em virtude da ausência de políticas que articulem organicamente a educação de jovens e adultos às redes públicas de ensino básico, não há carreira específica para educadores desta modalidade educativa. A situação mais comum é que os docentes que atuam com os jovens e adultos sejam os mesmos do ensino regular que, ou tentam adaptar a metodologia a este público específico, ou reproduzem com os jovens e adultos a mesma dinâmica de ensino aprendizagem que estabelecem com crianças e adolescentes.

Em geral, à docência em turmas de educação de jovens e adultos é utilizada para complementar em período noturno a jornada de trabalho dos docentes que atuam com crianças e adolescentes no período diurno. A rotatividade de docentes e a inexistência de equipes especialmente dedicadas à educação de jovens e adultos impede a formação de um corpo técnico especializado e dificulta a organização de projetos pedagógicos específicos para esta modalidade, limitando as possibilidades e os resultados de eventuais iniciativas de capacitação em serviço.

Como a educação de jovens e adultos ainda não constituiu um mercado de trabalho atrativo para os profissionais do ensino, é raro que a formação pedagógica inicial nos cursos técnicos de magistério de nível médio ou de Pedagogia em nível superior ofereçam opção de habilitação específica para essa modalidade educativas, ou até mesmo que contemplem em seu currículo conteúdos referidos a esse ciclo de vida e suas necessidades de aprendizagem específicas (DI PIERRO; GRACIANO, 2003, p. 23). 


\section{A estrutura do projeto}

O PEIS apresenta uma metodologia diferenciada à Modalidade EJA e como principal objetivo oferecer ao educando jovem, adulto ou idoso uma educação que 0 faça participante ativo do seu processo de ensino e aprendizagem, por meio do uso das tecnologias da informação, visando à construção e ao exercício da cidadania e, principalmente, à sua integração social. A proposta metodológica do projeto tem como princípio educativo, os saberes trazidos pelo educando intercalados ao conhecimento científico presente na figura do educador.

As atividades acontecem somente aos sábados (seguindo o calendário de aulas da Unicamp), no período da manhã (das $8 \mathrm{~h} 30 \mathrm{~min}$ às $13 \mathrm{~h}$ ), em quatro salas de aula no Prédio Anexo da Faculdade de Educação-UNICAMP, localizado na Unicamp, Município de Campinas-SP.

O PEIS utiliza a infraestrutura de um laboratório de informática e de quatro salas de aula, equipadas com data-shows além de dispositivos do cotidiano dos educandos, como smartphones. Atualmente, o laboratório de informática possui 30 computadores com acesso à Internet, Windows e pacote Office, além de uma lousa digital.

A equipe do projeto é formada por uma coordenadora, seis bolsistas SAE Serviço de Apoio ao Estudante, oito voluntários e um número variável de educandos dos cursos de Pedagogia e Licenciaturas da Unicamp que fazem seus estágios no projeto. Entre os voluntários há a presença de doutorandos, mestrandos e outros profissionais formados em Pedagogia, Geografia e História. Quanto aos cursos que estes frequentam se destacam os de Doutorado e Mestrado em Educação, Licenciatura em Matemática, Linguística, Licenciatura em Letras, Pedagogia, Licenciatura em Física, Licenciatura em Química e Ciências Sociais.

A inclusão digital ocorre através de aulas teóricas e práticas nos horários estabelecidos e agendados junto ao laboratório de informática, onde os educandos contam com a presença dos bolsistas monitores e também com períodos nos quais os educandos poderão praticar a interação com os computadores e as funcionalidades de acesso à Internet.

A coordenação faz a discussão com os educadores sobre a dinâmica das aulas, do trabalho docente com o educando jovem, adulto ou idoso, do controle da frequência e, principalmente, da necessidade do registro das atividades desenvolvidas no projeto em reuniões semanais conjuntas. Nesse espaço, o diálogo é o mais importante e não há hierarquia. O trabalho da coordenação é o de promover os encontros pedagógicos. Nesses encontros, educandos e educadores posicionam-se em círculo onde todos podem expor seus trabalhos em sala de aula e todas as decisões são discutidas em conjunto. 0 resultado das reuniões pedagógicas auxilia no sentido de orientar sobre as formas de apresentação dos conteúdos e da necessidade do planejamento das aulas. 
Os educadores são responsáveis pela manutenção e organização das salas de aula e do Laboratório de Informática, sendo eles que ligam e desligam todos os equipamentos, fazem o planejamento das aulas e a frequência dos educandos.

No período da tarde, quinzenalmente aos sábados, acontecem as reuniões pedagógicas, destinadas aos educadores e a coordenação. É abordada a leitura de um texto teórico, buscando estabelecer uma relação entre a teoria e a prática desenvolvida, além de serem discutidos os possíveis problemas enfrentados no decorrer das atividades. Nas reuniões, há também uma preocupação com o planejamento das aulas no decorrer do semestre.

As aulas são norteadas pelo tema gerador, escolhido em regime de votação aberta, entre educandos, educadores e coordenação, no primeiro dia de aula de cada semestre. Os temas geradores propiciam uma maior interação entre todos os participantes do projeto, pois, os educandos e educadores passam a pensar e observar sua realidade para contribuir com as aulas. Durante o primeiro semestre de 2015, o tema gerador proposto pela coordenação foi "Inclusão Digital".

Nos intervalos da aula o projeto oferece um lanche coletivo para educandos e educadores. $O$ lanche funciona como um elemento de integração entre os próprios educandos e entre educandos e educadores. O lanche antecede a Socialização, em que todos participantes dão sequência às atividades.

O diálogo entre educandos, educadores e coordenação constitui a "Socialização". É um mecanismo para nortear as práticas. O horário de estudo na sala de aula e no laboratório de informática é dividido por um intervalo com um lanche coletivo para todos os educandos e educadores e, em seguida, realiza-se a Socialização. Durante a Socialização, educandos e extensionistas discutem e trabalham um tema específico em forma de palestra, podendo ser realizada pelos extensionistas ou por convidados.

A atividade de Socialização é um momento de fundamental importância, podendo até ser considerado o "coração" do projeto. A Socialização se assemelha ao Círculo de Cultura, proposto por Paulo Freire, onde todos partilham dos mesmos questionamentos e aprendem juntos. Todos se sentem integrados no estudo do Tema Gerador, visualizando-se educadores sentados ao lado do seu educando e educandos rodeados de colegas, cujo interesse maior é saber mais.

Durante as Socializações do primeiro semestre de 2015 foram trabalhados pelos educandos e educadores os seguintes assuntos: A história do computador, a história da internet e fundamentos da utilização dos computadores, o uso de dispositivos de gravação como pendrives, DVDs e CDs, o uso do computador como ferramenta de escritório, os conceitos básicos de navegação na Internet e como procurar conteúdo na Internet, como utilizar o email; como usar e navegar nas Redes Sociais, as noções de cidadania na Internet, como declarações da Justiça Eleitoral e Defesa do Consumidor, o funcionamento básico de dispositivos móveis 
DOI: 10.12957/e-mosaicos.2017.30907

como smartphones, as noções de segurança na Internet e como os temas transversais de conteúdo do Ensino Fundamental e Ensino Médio ser relacionam com as tecnologias da informação. Estes temas foram abordados na forma de apresentações multimídia, com a utilização de datashow, vídeos e imagens.

O Estudo do Meio é uma aula in loco que acontece no penúltimo sábado de cada semestre, onde todos os educandos e educadores veem na prática tudo o que foi estudado ao longo do semestre. Essa atividade busca o trabalho coletivo e interdisciplinar, inspira confiança na equipe e motivação para aprofundamentos por parte dos educandos. Inicia-se dentro da sala de aula, com discussões da realidade a ser estudada e termina também a sala de aula, quando os educandos e educadores retomam os aspectos significativos da atividade.

Para estimular o aprendizado da inclusão digital, a comunicação entre educandos, educadores e coordenação é realizada através de grupos de discussão e e-mails cadastrados no Google Groups e também pelo software Whatsapp.

\section{Perfil do Educando do Projeto}

O perfil de educando(a) que frequenta as salas de aula do projeto é formado em sua maioria por jovens e adultos de baixa escolarização, adultos e idosos e pessoas oriundas da modalidade da Educação de Jovens e Adultos e pertencentes à comunidade.

No primeiro de semestre de 2015 o projeto teve dezessete educandos matriculados. Sendo quinze mulheres e dois homens. Quanto à faixa etária variou entre os dezoito anos completos e os setenta e oito anos completos. Quanto ao estado civil seis são solteiros(as), seis são viúvas (todas mulheres), três casados(as) e dois separados ou divorciados. Dez educandos(as) trabalham, quatro não trabalham, três são aposentados(as). Das funções desenvolvidas para os que ainda trabalham foram citadas: servidora pública, trabalhador da construção civil, doméstica, faxineira, mestre de conservação e manutenção, babá e diarista. Em sua maioria moradores de Campinas, mas também dos municípios de Hortolândia, Sumaré, Monte Mor e Valinhos, municípios que compõem a região metropolitana de Campinas.

Dos dezessete, somente uma educanda se encontrava também matriculada em uma escola da Fundação Municipal para Educação Comunitária (FUMEC) da Prefeitura de Campinas e o restante não concluiu o Ensino Fundamental ou o Ensino Médio. Desta forma, nove foram matriculados no Ensino Fundamental e oito no Ensino Médio.

No segundo semestre de 2015 o projeto teve trinta e seis matrículas, sendo que dez foram educandos(as) do primeiro semestre que retornaram ao projeto. Quanto a faixa etária variou entre os dezessete anos completos aos setenta e três anos completos. Quanto ao estado civil dez não quiseram informar, onze são solteiros(as), oito são casados(as), cinco viúvos(as) e dois divorciados(as). Dezoitos 


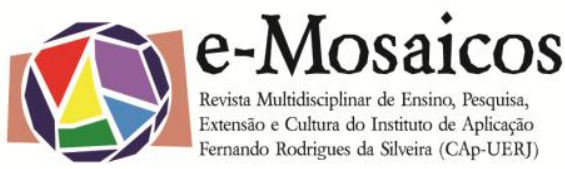

DOI: 10.12957/e-mosaicos.2017.30907

educandos(a) trabalham, catorze não trabalham, três estão aposentados(as) e uma é pensionista. Das funções desenvolvidas para os que ainda trabalham foram citadas: empregada doméstica, barrista, atendente, cozinheira, cabeleireiro, babá, copeira, trabalho em limpeza, em restaurante e auxiliar administrativo. Em sua maioria moradores de Campinas, mas também dos municípios de Hortolândia, Sumaré, Valinhos e Monte Mor.

\section{CONSIDERAÇÕES Finais}

O projeto possui um papel diferenciado ao olhar para os educandos(as) com idade acima de 50 anos como pessoas ativas e capazes de aprender e ensinar. 0 programa vai na "contramão" das diretrizes governamentais para a Modalidade EJA, que oferece atividades para os indivíduos que estão compreendidos na faixa etária de 15 a 29 anos e, que, por isso, marginaliza os que se encontram acima dessa faixa etária.

Do ponto de vista da extensão universitária, os impactos da abordagem de inclusão digital permitem destacar a percepção nos jovens e adultos do uso das tecnologias de informação como forma de inclusão social e melhoria da qualidade de vida. Também visam proporcionar, especialmente para os adultos e idosos, a retomada de papéis significativos e importantes dentro da sociedade, retirando-os do isolamento e da inatividade ou falta de perspectivas. Além disso, o projeto torna-se um atrativo para o público de jovens, adultos e idosos de baixa escolarização como porta de entrada para outros cursos associados à Educação de Jovens e Adultos disponíveis na Unicamp.

Do ponto de vista da pesquisa acadêmica, o Projeto permite aos bolsistas exercer a prática pedagógica e a didática na sua formação de educador. Proporciona a percepção da peculiaridade do público de EJA e as especificidades que estes educandos demandam. O Projeto está inserido no Grupo de Pesquisa GEPEJA da Faculdade de Educação da Unicamp e se propõe a fortalecer o tripé ensino, pesquisa e extensão dando oportunidade aos estudantes dos cursos de licenciatura e de Pedagogia para estabelecer práticas em experiências reais. Mais especificamente, pretende apresentar para os bolsistas o uso do computador e dispositivos móveis como uma tecnologia capaz de transformar os modos de conhecer novos ambientes de conhecimento, na produção de novos espaços e permitir diversas práticas de construção coletiva visando à inclusão digital.

Do ponto de vista da formação e ensino, o projeto é um espaço que se apresenta como uma alternativa de vivência prática para esse futuro educador em um ambiente onde ensino, pesquisa e extensão estão voltados para contribuir para a formação do educador através da vivência da prática e da pesquisa. Proporciona uma formação real através da oportunidade de aliar os conhecimentos teóricos as características de uma modalidade que possui características próprias. Além disso, permite ao futuro educador repensar a prática pedagógica, desenvolver autonomia 
DOI: $10.12957 /$ e-mosaicos.2017.30907

através do trabalho interdisciplinar e colaborativo através da formação e do contato direto com a obra de Paulo Freire.

Ainda hoje a maioria dos cursos de licenciatura não trabalha com a temática do educando adulto, tendo sua didática, suas metodologias e sua psicologia da aprendizagem com ênfase no ensino e aprendizagem da criança e do adolescente. Diante dessa lacuna em sua formação, é comum o educador ter dificuldade ao se deparar com uma sala de jovens, adultos e idosos. O Projeto Educativo de Integração Social - PEIS - procura, através da formação teórica baseada no estudo das obras de Paulo Freire, conciliar teoria e prática, proporcionando ao futuro educador a oportunidade de vivenciar o laboratório prático de toda sua formação teórica, aliada a uma prática real e possível.

\section{REFERÊNCIAS BIBLIOGRÁFICAS}

BEISIEGEL, Celso de Rui. A política de educação de jovens e adultos analfabetos no Brasil. In. OLIVEIRA, Dalila Andrade (org.). Gestão democrática da educação: desafios contemporâneos, $2^{\circ}$ ed. Petrópolis: Vozes, 1998.

BRASIL. Parecer CEB nº 11/2000. Diretrizes Curriculares Nacionais para a Educação de Jovens e Adultos. 2000.

DELORS, J et al. Educação: um tesouro a construir. Relatório para a UNESCO da Comissão Internacional sobre Educação para o século XXI. 9 ed. São Paulo: Cortez/ UNESCO/MEC, 2004.

DI PIERRO, Maria Clara; GRACIANO, Mariângela. A educação de jovens e adultos no Brasil: informe apresentado à Oficina Regional da UNESCO para a América Latina e Caribe. São Paulo: Ação Educativa, junho de 2003.

FREIRE, Paulo. $A$ importância do ato de ler: em três artigos que se completam. São Paulo: Autores Associados, 1989.

. Pedagogia da autonomia: saberes necessários à prática educativa. São Paulo: Autores Associados, 1996.

Educação como prática da liberdade. Rio de Janeiro: Paz e Terra, 2011.

HADDAD, Sérgio. A educação de pessoas jovens e adultas e a nova LDB. In.:

BRZEZINISK, Iria (org.). LDB Interpretada: diversos olhares se entrecruzam. São

Paulo; Cortez, 2002.

GADOTTI, Moacir. A CONFINTEA VI no contexto do Brasil e da América Latina: uma oportunidade para a Educação Popular. 2009. Disponível em http://www.forumeja.org.br/to/?q=node/82 . Acesso em 12 de junho de 2010. 
IBGE. Atlas do Censo 2010. 2010. Disponível em: http://censo2010.ibge.gov.br/apps/atlas/. Acesso em: 01 de setembro de 2014.

LEITE, Sandra Fernandes. O Direito à Educação Básica para Jovens e Adultos da Modalidade EJA no Brasil: Um resgate histórico e legal. Tese (Doutorado em Educação). Universidade Estadual de Campinas, SP, 2013. Disponível em: http://www.bibliotecadigital.unicamp.br/document/?code=000910013. Acesso em: 10 de abril de 2014.

LEITE, Sandra Fernandes; SOUZA, Carlos Roberto. Relato de Experiência no Projeto Educativo de Integração Social-PEIS: uma alternativa metodológica para a Educação de Adultos. In: Simpósio do Grupo de Estudos e Pesquisas em Educação de Jovens e Adultos. 3. Itatiba-SP. 2010.

RIBEIRO, Vera Masagão. A formação de educadores e a constituição da educação de jovens e adultos como campo pedagógico. Revista Educação e Sociedade, vol. 20, n $68,1999$.

SOUZA, Andressa Luiza de. (Re)construindo os perfis dos educandos no Projeto Educativo de Integração Social-PEIS: análise das fichas de inscrição no período de 1998 a 2012. Trabalho de Conclusão de Curso. Instituto de Estudos da Linguagem. Universidade Estadual de Campinas. Campinas-SP. 2013.

SOUZA, Andressa Luiza de. Relato de Experiência: Projeto Educativo de Integração Social-PEIS. In: Simpósio do Grupo de Estudos e Pesquisas em Educação de Jovens e Adultos. 4. Campinas-SP. 2012.

SOUZA, Carlos Roberto. As vozes dos educandos do Projeto Educativo de Integração Social-PEIS. Dissertação (Mestrado em Educação). Faculdade de Educação. Universidade Estadual de Campinas. Campinas-SP. 2011.

UNICAMP. Serviço de Apoio ao Estudante (SAE). O que é o SAE? Disponível em: https://www.sae.unicamp.br/portal/index.php?option=com_content\&view=article\&id $=31 \&$ Itemid $=128$. Acesso em: 09 de setembro de 2015 . 